\title{
Doctor Herb: A Mobile Game Application
}

\author{
Edwin S. de Guzman, Niña Ciela Florentino, Denzel Lewis Madrideo, Karl Santos
}

\begin{abstract}
Dr. Herb: A Mobile Game Application is a game project designed for the game users who have a lack of knowledge and information about the effects of herbal medicine on our body.

The system is designed to help the game users to have knowledge and information about the ten (10) herbal medicines in the country, Philippines. During the game, every captured medicine will have its information or a brief description. Each mission has its own goal to finish before heading to the next mission. A challenge of time is included, the obstacle course is around the environment and lastly, a player can get additional health to his character.

The Administrator has the capacity to control all the components in the system such as editing the game, adding and removing features and to check the game system application. The researchers used a spiral model as it matches the processes of the game. There are two (2) users in the system: the administrator of the game and the game users. The users needed to use a Bluetooth connection to get the Android Package Kit (APK) and install it to their cellphone devices to play the game.

The researchers conducted an evaluation that aims to test the developed game. There were thirty (30) Users, five (5) Medical Practitioners and five (5) IT experts to test the developed game. The result of the evaluation was marked as Excellent and Very Good in terms of functionality, reliability, usability, efficiency, maintainability, and portability.
\end{abstract}

\section{INTRODUCTION}

Modern technology has made the requirements for information flow to be quick and effective. People have been able to achieve this through internet, the medium etc. The internet has facilitated each of us, by making the communication cheap and fast. The growth of the internet is a necessity nowadays. Now, the internet, where people choose to spend a major part of their day has brought social communities where people can chat, message, share beliefs, extract information, share information about things they are interested in. Technology have the biggest part in every people's life in today's generation. Living in the 21 st century, people obviously meet the huge stream of information

Being too focus on modern technology sometimes harm people in a way that they, sometimes get sick. Some people, mostly teenagers, stayed more than they should, in front of their computers or other technological devices. As a result, the chance to eat in the right time would be avoided and people will end up getting some sickness. And here in the Philippines, it sometimes gets really hot and sometimes it rains. People sometimes can get sick with these kinds of

Revised Version Manuscript Received on 10 September, 2019.

Mr. Edwin S. de Guzman, Manila Central University, Philippiness.(E: mail : mcucbt.dwindeguzman@gmail.com)

Ms. Niña CielaFlorentino, Manila Central University (E: Mail : nina_ciela@yahoo.com)

Mr. Denzel Lewis Madrideo, Manila Central University, Philippiness.(E- mail : leznedmadrideo18@gmail.com)

Mr. Karl Santos.Manila Central University, Philippiness (E-mail karl_santos@yahoo.com) everyday.

weather. Sickness or disease comes into our life in an unexpected way. Sometimes it comes in a bad time. Sometimes you experience more than one disease at the same time. It is recommended that people, should always be ready and have the knowledge unto what to take and what to not take when a certain kind of disease comes into someone's life. The processes of the project is to know what other methods can do or can make to heal an illness without chemical uses and technical materials, but only with just the use of natural methods.

Doctor herb is a modern 3D graphics mobile game application that will help users to find out the herbal medicine they need for their lives by the use of a certain quest or mission within the game.

\section{PROJECT CONTEXT}

Some people forget what herbal medicines that can find in different places and can be used for a particular disease or sickness. The developed system aims to remind or provide new and helpful information to people about herbal medicines in a way of entertainment through a mobile game application.

Additionally, by the way of displaying information of effectiveness of certain kinds of herbal medicine, the developed system suggested the users to use herbal medicine as subject.

Moreover, the developed system intended to provide an effective and helpful information in the field of herbal medicines in a way that users can differentiate the use of chemical medicines and herbal medicines, so that they can act in the right way of treating someone or taking care of sick people.

\section{OBJECTIVES OF THE STUDY}

\section{General Objective}

The general objective of the study is to develop and design a mobile game application entitled Doctor Herb.

\section{Specific Objectives}

The developed system specifically aims:

- To develop a mobile game application that would educate players about the herbal medicines.

- To develop a mobile game application that will give entertainment to the users.

- To develop a mobile game application that is a user-friendly.

- To develop a mobile game application that will help users to appreciate the value of herbal medicines. 


\section{SIGNIFICANCE OF THE STUDY}

Some particular herbal medicines are effective in certain curable diseases and a lot of researchers regarding this matter conducts their study with certain areas. Since almost every people owns a mobile device, it is wise for people to develop an application that will be health-based in order for people to be aware and ready whenever an illness or sickness comes into one's life. The proponents understand this matter which leads them to a decision of developing a mobile game application relating to herbal medicines that would be significant to certain areas. The developed system is significant to the following areas:

a) To Android Users, the study is seen significant to the android users for it will help them to know and gain more knowledge about different herbal medicines.

b) To Future Researchers, the study is seen significant to the future researchers because they would gain additional attainments and skill in conducting a research.

c) To Proponents, the study is seen significant to the proponents because they would gain additional knowledge and help them improve their skills in developing a program or an app.

d) To Medical Practitioners, the study is seen significant to the people in medical field because it may serve as reference when there is a related herbal medicines topics.

\section{SCOPE AND LIMITATION}

All systems that were developed in this world have their own capacities. They are made to function only into their certain capabilities. Developers or programmers have a hard time enlarging, upgrading, or evolving their systems. Some people uses mobile devices for different purposes such as playing games, listen to music, chat with friends etc. Mobile applications also has its own capacities. Some applications cannot function in a personal computer. Some are free to download, and some are needed to be paid.

The scope of the developed system, it is a mobile game application called Doctor Herb. It is made to only work on android version 4.4 and above. It can be downloaded in its own Android Package Kit (APK). The proponents used UNITY as game engine to developed this system and within player preference setting in UNITY as the save and load management of the game. In the developed system, there would be user levels which are admin and players. The admin has the capacity to access and control all the components of the developed system. The players has the capacity to control the characters. The limitations of the developed system is that be viewed horizontally only. The developed system can play through offline. The game has only one map with three different missions. The game works only in the version some settings in the system. The system is designed to help the game users to have knowledge and information about the ten (10) herbal medicines in the country, Philippines. During the game, every captured medicine will have its information or a brief description. Each mission has its own goal to finish before heading to the next mission. A challenge of time is included, the obstacle course is around the environment and lastly, a player can get additional health to his character.

The limitations of the developed system is that it cannot be 2018.1.3f1 of unity engine software to rework or change

viewed vertically. The system does not have cross-platform capabilities. It does not have the versatility to work on IOS and lower versions of android. Users cannot make their own character in the game. The game has only one map with three different missions. There is no database needed in the developed system to store mission and current status of characters.

\section{CONCEPTUAL FRAMEWORK}

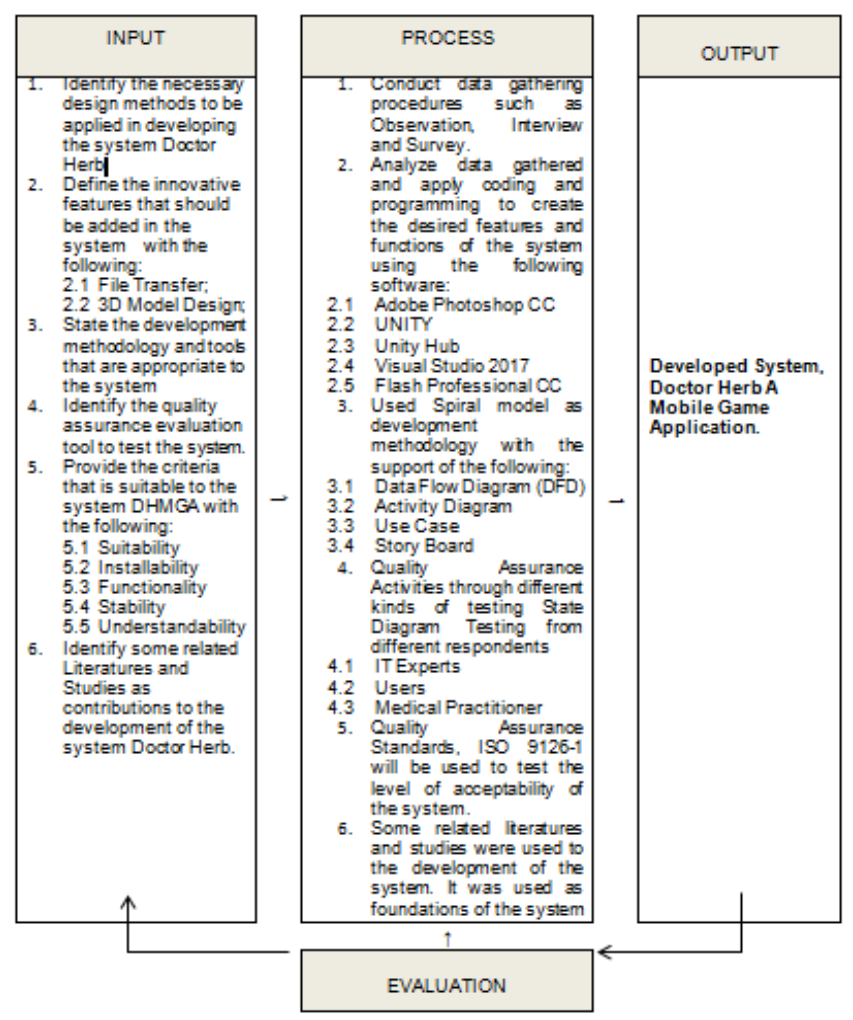

Figure 1. Conceptual Framework

\section{METHODS}

\section{Software lifecycle}

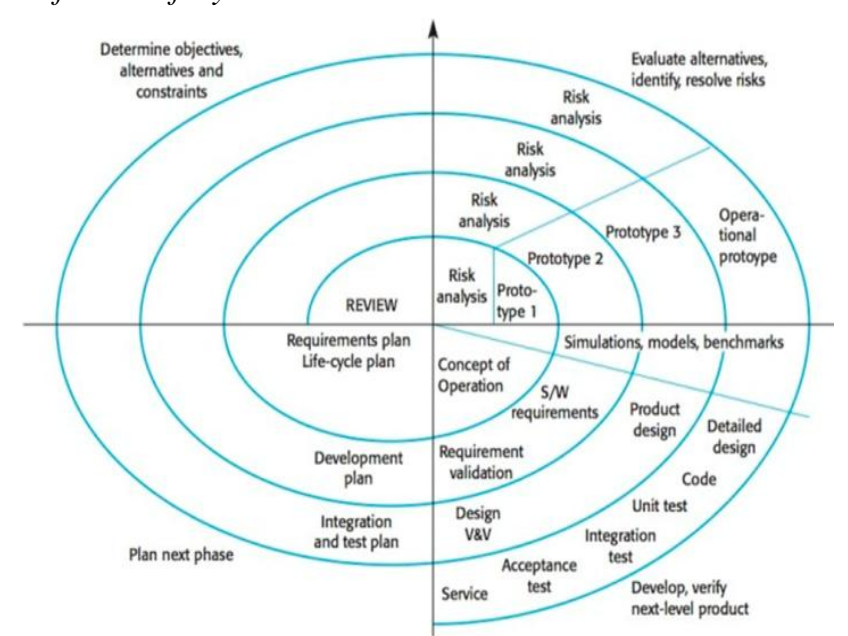

Figure 2. Spiral Model

The spiral model combines change avoidance with change tolerance. It assumes that changes are a result of project risks 
and includes explicit risk management activities to reduce these risks. Each loop in the spiral is split into four sectors:

1. Objective setting. Specific objectives for that phase of the project are defined. Constraints on the process and the product are identified and a detailed management plan is drawn up. Project risks are identified. Alternative strategies, depending on these risks, may be planned.

2. Risk assessment and reduction. For each of the identified project risks, a detailed analysis is carried out. Steps are taken to reduce the risk. For example, if there is a risk that the requirements are inappropriate, a prototype system may be developed.

3. Development and validation. After risk evaluation, a development model for the system is chosen. For example, throw-away prototyping may be the best development approach if user interface risks are dominant. If safety risks are the main consideration, development based on formal transformations may be the most appropriate process, and so on. If the main identified risk is sub-system integration, the waterfall model may be the best development model to use.

\section{Use Case Diagram}

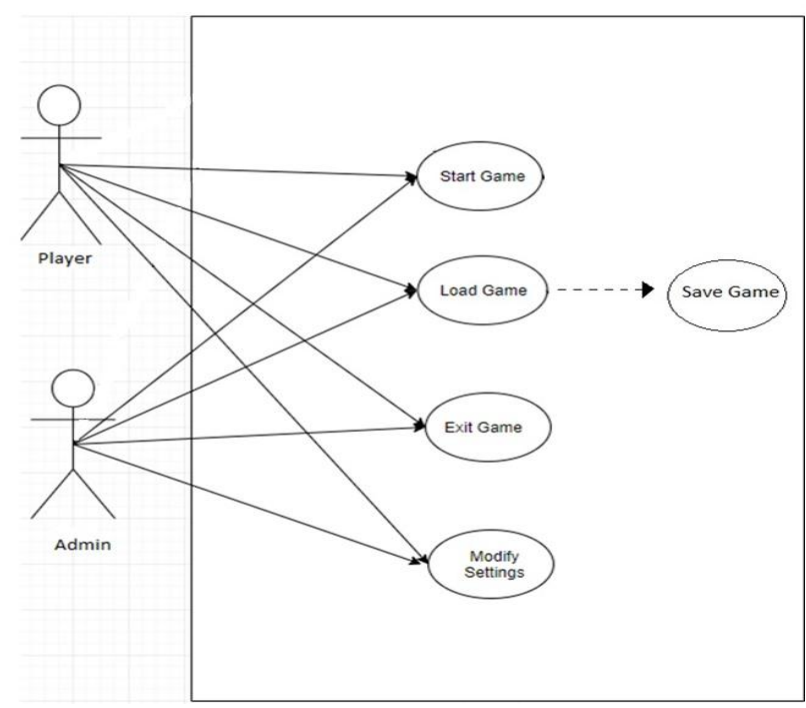

Figure 3 Use Case Diagram of Dr. Herb

The figure shows the scope of each user in the developed system

\section{Research Materials and Methods}

\section{Procedures}

The researchers of the study conducted methods such as brainstorming, consultation, research, and interview for the development of Dr. Herb.

1. Brainstorming - Brainstorming is a group creativity technique by which efforts are made to find a conclusion for a specific problem by gathering a list of ideas spontaneously contributed by its members. The researchers will use this method to interact with each other, to discuss how to develop the system and how to solve problems that will encounter.

2. Consultation - The researchers will use this method to consult their adviser, professors, and thesis coordinator to know their recommendations for the improvement of the study

3. Internet Research - it is the practice of using Internet information, especially free information on the World Wide
Web. The researchers will use this method for gathering data and information from the internet. It will also use for the source codes for developing the system.

4. Interview - Interview is a conversation where questions are asked and answers are given. The researchers will use this method for gathering information and recommendations from the professionals for the improvement of the study.

\section{Statistical Treatment of Data}

Statistics is important for getting the organized information. It includes analyzing, implementing, and interpreting numerical data. Statistical treatment of data is essential in order to make use of the data in the right form.

\section{Frequency and Percentage}

It is a numerical analysis to derive or compare magnitudes. This was applied in analyzing the answer of the respondents with respect to the problem.

\section{Using Manual System}

$$
\begin{aligned}
& \text { Where: } \\
& \begin{array}{l}
\mathrm{P}=\text { Percentage } \\
\mathrm{f}=\text { frequency } \\
\mathrm{n}=\text { no. of respondents }
\end{array}
\end{aligned}
$$

\section{RESULTS AND DISCUSSION}

This section discusses the analysis and interpretation of data as well as the findings of the conducted evaluation. The detailed tally result of users, medical practitioners and IT experts that use the system is discussed in this section.

Forty (40) different people evaluated the Doctor Herbs. Almost all of them rated the system with "Excellent" and some with "Very Good".

Table 1 Likert Scale Evaluation for Doctor Herbs

\begin{tabular}{|c|c|}
\hline NUMERICAL RATING & EQUIVALENT \\
\hline 5 & Excellent \\
\hline 4 & Very Good \\
\hline 3 & Satisfactory \\
\hline 2 & Needs Improvement \\
\hline 1 & Poor \\
\hline
\end{tabular}

Table 4.0 shows the rating of 5 Excellent, 4 Very good, 3 Satisfactory, 2 Needs Improvement and lastly, 1 Poor

Table 2 Mean Range Values

\begin{tabular}{|c|c|}
\hline VALUES & RATING SCALE \\
\hline Excellent & $4.5-5.00$ \\
\hline Very Good & $3.5-4.49$ \\
\hline Satisfactory & $2.5-3.49$ \\
\hline Needs Improvement & $1.5-2.49$ \\
\hline Poor & $1-1.49$ \\
\hline
\end{tabular}

Table 4.1 shows the rating of "Excellent" ranged from 4.5 to 5.00 , while 3.5 to 4.49 "Very Good", 2.5 to 3.49 "Satisfactory", however 1.5 to 2.49 "Needs Improvement" and lastly 1.00 to 1.74 for "Poor" 
Table 3 Detailed Mean Tally Result of the Doctor Herbs (Users)

\begin{tabular}{|c|c|c|}
\hline CRITERIA & \multicolumn{2}{|c|}{ RATING } \\
\hline FUNCTIONALITY & Mean & Description \\
\hline $\begin{array}{l}\text { 1. Functions required for the application are } \\
\text { implemented (sustainability) }\end{array}$ & 4.90 & Excellent \\
\hline 2. Functional accuracy is provided (accuracy) & 4.72 & Excellent \\
\hline $\begin{array}{l}\text { 3. Functions have met with the specifications } \\
\text { (compliance). }\end{array}$ & 4.72 & Excellent \\
\hline $\begin{array}{l}\text { 4. Connecting with other systems and } \\
\text { application is provided (interoperability). }\end{array}$ & 4.62 & Excellent \\
\hline 5. Substantial security is provided. & 4.69 & Excellent \\
\hline RELIABILITY & Mean & Description \\
\hline $\begin{array}{l}\text { 1. Application has minimal to no bug } \\
\text { (maturity). }\end{array}$ & 4.76 & Excellent \\
\hline $\begin{array}{l}\text { 2. A certain system level is maintained even } \\
\text { when a trouble occurs (fault tolerance). }\end{array}$ & 4.69 & Excellent \\
\hline $\begin{array}{l}\text { 3. Normal operations are restored readily, } \\
\text { when a failure occurs (recoverability). }\end{array}$ & 4.56 & Excellent \\
\hline III. USABILITY & Mean & Description \\
\hline $\begin{array}{l}\text { 1. The application is easy to ope } \\
\text { (learnability). }\end{array}$ & 4.92 & Excellent \\
\hline $\begin{array}{l}\text { 2. Allows easy operation management } \\
\text { (operability). }\end{array}$ & 4.96 & Excellent \\
\hline
\end{tabular}

Table 4 shows the detailed mean tally of the evaluation. The developed system was evaluated by thirty (30) users on the following criteria functionality, reliability and usability. The table shows that the developed system was marked as excellent.

Table 5 Detailed Mean Tally Result of the Evaluation Doctor Herbs (IT Expert)

\begin{tabular}{|c|c|c|}
\hline CRITERIA & \multicolumn{2}{|c|}{ RATING } \\
\hline FUNCTIONALITY & Mean & Description \\
\hline $\begin{array}{l}\text { Functions required for the application are } \\
\text { implemented (sustainability) }\end{array}$ & 4.00 & Very Good \\
\hline Functional accuracy is provided (accuracy) & 4.40 & Very Good \\
\hline $\begin{array}{l}\text { Functions have met with the specifications } \\
\text { (compliance). }\end{array}$ & 4.60 & Excellent \\
\hline $\begin{array}{l}\text { Connecting with other systems and application is } \\
\text { provided (interoperability). }\end{array}$ & 4.40 & Very Good \\
\hline Substantial security is provided. & 3.60 & Very Good \\
\hline RELIABILITY & Mean & Description \\
\hline Application has minimal to no bug (maturity). & 4.40 & Very Good \\
\hline $\begin{array}{l}\text { A certain system level is maintained even when } \\
\text { a trouble occurs (fault tolerance). }\end{array}$ & 4.40 & Very Good \\
\hline $\begin{array}{l}\text { Normal operations are restored readily, when a } \\
\text { failure occurs (recoverability). }\end{array}$ & 4.60 & Excellent \\
\hline VI. USABILITY & Mean & Description \\
\hline The application is easy to operate (learnability). & 4.40 & Very Good \\
\hline Allows easy operation management (operability) & 3.60 & Very Good \\
\hline EFFICIENCY & Mean & Description \\
\hline $\begin{array}{l}\begin{array}{l}\text { Provides a good responses high throughput time } \\
\text { (time behaviour) }\end{array} \\
\text { (ing }\end{array}$ & 4.60 & Excellent \\
\hline Allows effective use of application resources & 4.40 & Very Good \\
\hline MAINTAINABILITY & Mean & Description \\
\hline $\begin{array}{l}\text { Allows easy analysis of design documents and } \\
\text { program when a bug is found (analysability) }\end{array}$ & 3.60 & Very Good \\
\hline $\begin{array}{l}\text { Allows easy expansion and modification of the } \\
\text { application (changeability) }\end{array}$ & 5.00 & Excellent \\
\hline $\begin{array}{l}\text { Modification of the application does not affect } \\
\text { others (stability) }\end{array}$ & 4.40 & Very Good \\
\hline $\begin{array}{l}\text { Laborious test are not required after a } \\
\text { modification has been made (testability) }\end{array}$ & 4.60 & Excellent \\
\hline VI. PORTABILITY & Mean & Description \\
\hline Provides flexible environment (adaptability) & 4.60 & Excellent \\
\hline \begin{tabular}{|l} 
Providing easy installation work (instability) \\
\end{tabular} & 4.40 & Very Good \\
\hline $\begin{array}{|llll|}\begin{array}{l}\text { Compliance } \\
\text { (conformance) }\end{array} & \text { with porting specifications } \\
\end{array}$ & 4.40 & Very Good \\
\hline
\end{tabular}

Table 5 shows the detailed mean tally of the evaluation. The developed system was evaluated by five (5) IT experts on the following criteria functionality, reliability and usability. The table shows that the developed system was accepted based from the result; majority of the feedback shows "Very Good".

Table 6 Detailed Result of the Evaluation of Doctor Herbs (Medical Practitioner)

\begin{tabular}{|c|c|c|}
\hline CRITERIA & \multicolumn{2}{|c|}{ RATING } \\
\hline VII. FUNCTIONALITY & Mean & Description \\
\hline 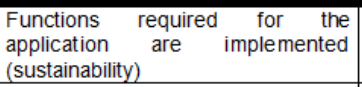 & 5.00 & Excellent \\
\hline $\begin{array}{l}\text { Functional accuracy is provided } \\
\text { (accuracy) }\end{array}$ & 4.80 & Excellent \\
\hline $\begin{array}{l}\text { Functions have met with the } \\
\text { specifications (compliance). }\end{array}$ & 4.80 & Excellent \\
\hline $\begin{array}{l}\text { Connecting with other systems and } \\
\text { application is provided } \\
\text { (interoperability). }\end{array}$ & 4.80 & Excellent \\
\hline Substantial security is provided. & 4.80 & Excellent \\
\hline VIII. RELIABILITY & Mean & Description \\
\hline $\begin{array}{l}\text { Application has minimal to no bug } \\
\text { (maturity). }\end{array}$ & 4.60 & Excellent \\
\hline $\begin{array}{l}\text { A certain system level is maintained } \\
\text { even when a trouble occurs (fault } \\
\text { tolerance). }\end{array}$ & 4.60 & Excellent \\
\hline $\begin{array}{l}\text { Normal operations are restored } \\
\text { readily, when a failure occurs } \\
\text { (recoverability). }\end{array}$ & 4.80 & Excellent \\
\hline IX. USABILITY & Mean & Description \\
\hline $\begin{array}{l}\text { The application is easy to operate } \\
\text { (learnability). }\end{array}$ & 5.00 & Excellent \\
\hline $\begin{array}{l}\text { Allows easy operation management } \\
\text { (operability). }\end{array}$ & 5.00 & Excellent \\
\hline
\end{tabular}

Table 6 shows the detailed mean tally of the evaluation. The developed system was evaluated by five (5) medical practitioners on the following criteria functionality, reliability and usability. The table shows that the developed system was accepted based from the result; majority of the feedback shows "Excellent".

Summary Result of the Evaluation

Table 7 Summary Tally of the Evaluation's Result (Users)

\begin{tabular}{|c|c|c|}
\hline CRITERIA & MEAN & DESCRIPTION \\
\hline Functionality & 4.73 & Excellent \\
\hline Reliability & 4.67 & Excellent \\
\hline Usability & 4.94 & Excellent \\
\hline
\end{tabular}

Table 7 shows the summary of the evaluation results of the parents. The mean is obtained by first finding the sum of all the mean numbers for each criteria then dividing it in the number of the criterion. The result shows that all the overall mean tally result is 4.78 , which falls under the description of an "Excellent" remark.

Table 8 Summary Tally of the Evaluation's Result (Medical Practitioner)

\begin{tabular}{|c|c|c|}
\hline CRITERIA & MEAN & DESCRIPTION \\
\hline Functionality & 4.84 & Excellent \\
\hline Reliability & 4.47 & Excellent \\
\hline Usability & 5.00 & Excellent \\
\hline
\end{tabular}

Published By: 
Table 8 shows the summary of the evaluation results of the teachers. The mean is obtained by first finding the sum of all the mean numbers for each criteria then dividing it in the number of the criterion. The result shows that all the overall mean tally result is 4.84 , which falls under the description of an "Excellent" remark

Table 9 Summary Tally of the Evaluation's Result (IT Experts)

\begin{tabular}{|c|c|c|}
\hline \multicolumn{2}{|c|}{ MERITERIA } & Very Good \\
\hline Functionality & 4.20 & Very Good \\
\hline Reliability & 4.47 & Excellent \\
\hline Usability & 4.00 & Very Good \\
\hline Efficiency & 4.50 & Excellent \\
\hline Maintainability & 4.40 & Excellent \\
\hline Portability & 4.47 & \\
\hline
\end{tabular}

Table 9 shows the summary of the evaluation results of the IT Experts. The mean is obtained by first finding the sum of all the mean numbers for each criteria then dividing it in the number of the criterion. The result shows that all the overall mean tally result is 4.34 , which falls under the description of a "Very Good and Excellent" remark.

\section{SUMMARY}

The proponents developed a system entitled, Doctor Herbs which aims to innovate the learning about herbal medicines. The developed system covers the fundamentals of the herbal medicines. The developed system provided description for each herbal medicine or plant. The developed system informed also the users about what are the missions to do for each quest or level. The software methodology is spiral which jives the processes of the developed system. The system has a character which aims to find and collect herbal medicines and plant. The system has different level with different obstacle to overcome. The proponents used Unity 3D, Adobe Photoshop and Visual Studio in the completion of the system. The system was evaluated by users, medical practitioner and IT experts to attain its basic objectives. The developed system was evaluated as excellent generally.

\section{RECOMMENDATION}

The proponents found out that there are still functions that need to be listed and included in the system. Based on the results of the evaluation conducted, majority find it helpful which are mostly the users. The following are the suggested and recommended functions in the future development and improvement of the system.

1. The system will include more stages and quests.

2. The system will add more obstacle course like timer, health percentage

3 . The system will add more animations to the character and herbal medicines

4. The system will have the chance to add and choose character.

5. The character will add weapon in picking up the plant.

6 . The system will be played through virtual reality device.

7. The system will be installed and played through IOS platform

\section{REFERENCES}

1. Isabella dela Torre, "Mobile Apps for Suicide Prevention: Review of Virtual Stores and Literature aims to study the existing mobile apps for suicide prevention in the literature and the most commonly used virtual stores." Mobile Apps for Suicide Prevention: Review of Virtual Stores and Literature, 2017

2. Christopher Lloyd Maquinto et.al, 2016), "Hospital information system with Mobile Technology utilizes mobile technology for nurse and doctor usage, which would help them monitor the status of each patient and update conditions easily. A user acceptance test was conducted among the users and the results were satisfactory. The research conclude that the proposed system would aid hospitals in managing patient health and requirements and can serve as a business model for both private and public health institutions. 